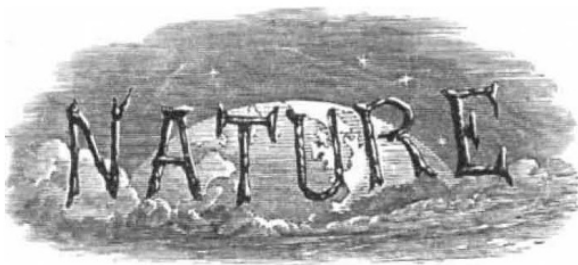

THURSDAY, SEPTEMBER I6, 1920.

Editorial and Publishing Offices:

MACMILLAN \& CO., LTD.,

ST. MARTIN'S STREET, LONDON, W.C.2.

Advertisements and business letters should be addressed to the Publishers.

Editorial communications to the Editor.

Telegraphic Address: PHUSIS, LONDON.

Telephone Number: GERRARD 8830.

\section{The British Association and National Life.}

VX ${ }^{\mathrm{E}}$ published a fortnight ago (Sept. 2, p. I3) some observations made by Dr. R. V. Stanford, our local correspondent for the recent meeting of the British Association at Cardiff, upon "the apathy of local people of the educated classes to the presence of the Association" in the city, and the neglect of the opportunity which such a meeting may afford of stimulating public interest in scientific achievements and their applications. There is, we believe, a feeling among many members of the Association that efforts should be made to increase its usefulness by bringing it into closer contact with thoughtful members of all classes of the community and encouraging a fuller representation of the new generation of scientific workers. Institutions, like organisms, must be adapted to their circumstances, or suffer eventual extinction. The British Association is still in a state of strong vitality, but it is not making progress; and not to be in touch with advancing times signifies retrogression.

It is easy to be satisfied with this condition, and to consider that all is of the best in the best of all scientific organisations, but that is not the spirit of development. There is no need for scientific men now to work in secret cells, and carry on their discussions in conclaves; on the contrary, the world is more eager than ever it was to learn and to use the results of scientific research. Whatever apathy exists on the part of the general NO. 2655, VOL. IO6] public as regards these advances is due largely to the neglect of national bodies like the British Association to adjust themselves to changing national needs. The public does not understand the Association, and the Association makes little endeavour to show the bearing of scientific methods and principles upon most subjects of vital importance in national polity and industrial affairs.

When the Association was founded, in 1831 , one of its first purposes was stated to be "to obtain a greater degree of national attention to the objects of science"-a phrase which in the present rules reads "to obtain more general attention for the objects of science." Whether the change was deliberate or not we do not know, but we prefer to think that "national attention" is what was originally intended, and we desire to urge that this aspect of the Association's activities should be given more consideration than it now receives, instead of concentrating upon the work of the sections. There were no sections when the Association began its existence, but only committees upon various branches of science. At the Cambridge meeting in 1833 the sections were: (I) Mathematics and Physics; (2) Philosophical Instruments and Mechanical Arts; (3) Natural History, Anatomy, Physiology; (4) History of Science. Chemistry, with Mineralogy, became a section in the following year, and Statistics formed a sixth section. Then came in succession Geology and Geography, Zoology and Botany, Mechanical Science, and various other changes, leading to the present denomination of sections. Anthropology became a section in 1884 , Physiology ten years later, Botany in 1895, Educational Science in I901, Agriculture in I9r2, and at the recent Cardiff meeting the General Committee recommended that Psychology be promoted from a sub-section to a section, making thirteen in all. Each section is autonomous, and there is no co-ordinating committee to make them part of a composite organisation, or suggest how they may combine their forces for the common good. The Association is like a great industrial works in which each shop produces what it pleases, and no one has the duty of building up a noble structure from the various parts.

Two separate functions may be distinguished in the work of each section. One is the presentation of papers for discussion by workers in the particular fields to which they refer, and half-a-dozen such allied workers gathered together can gain more from one another by informal conversation than can possibly be elicited when their remarks are addressed to an audience without special know- 
ledge of the subjects under consideration. If, however, a section is to be regarded purely as an assembly of specialists, and papers read are prepared on this assumption, then fifty sections would not be sufficient to meet the present-day differentiation of scientific subjects. As such subdivision is impracticable, intensive discussion is usually impossible, and very few members of a section are able to make profitable comments upon papers of a specialised kind. Authors ought not, indeed, to assume that a section as a whole consists of specialists in their own minute fields, but should address themselves rather to workers generally in a broad department of scientific activity. Members who attend any particular section do not expect to learn much that is new of their own special subjects, but they do want to know the chief lines of progress in related branches of work. A section ought not, in fact, to be addressed as a scientific or technical society, but as a Royal Institution assembly. Its main function should not be technical discussion by specialists for specialists, but the enlightenment of an extensive group of workers as to main lines of advance in fields not specifically their own.

We know, of course, that there are practical difficulties in ensuring generally intelligible discourses from men whose main interest is in actual research. Genius for discovery is not often associated with the art of literary or of vocal expression, so that it is not uncommon to find readers of papers and openers of discussions in sections offending the most elementary principles of public speaking. They converse with themselves instead of addressing the back row of their audience; if they use a lantern their slides are often mixed, and are usually changed by the irritating instruction "Next, please," long ago discarded by every public lecturer of any reputation; and if they use a blackboard, what they scribble upon it can be read by the front row only. All these sins of commission, as well as others of omission, may be forgiven when a circle is small and those who compose it are familiar with the details of the subject, but an audience which fills a section room has a right to expect its interests to be considered, and not to leave the room with a feeling of disappointment or in a more confused state than when they entered it.

There would not be the slightest difficulty in securing large audiences for joint meetings of several sections, interested in different aspects of broad scientific subjects, provided that reasonable care were devoted to the selection of the subjects and the opening speakers. The success of the symposia arranged by the Faraday Society through Sir Robert Hadfield's enterprise shows how keen scientific workers are to occupy a common platform and understand each other's contribution to a common cause. The organising committees of related sections of the British Association would perform a much greater service to the scientific community by united action on these lines than by accepting as their separate programmes a variety of papers of which few are novel or of wide interest. The separate action of sections upon matters of common interest was exemplified by four resolutions brought before the General Committee at Cardiff. The Section of Zoology condemned the views of the "Investigators" of the Secondary Schools Examination Council of the Board of Education that zoology was not so suitable as botany as a school subject; the Section of Geography asked that geography should be recognised by the Board as a subject for advanced courses in secondary schools; and that of Anthropology urged that work of a regional survey type should receive official encouragement and anthropometric measurements should be made of pupils in continuation schools. There is an Educational Science Section of the Association where all these subjects could be considered appropriately in joint session with the sections which brought them forward, yet the action was taken independently and without consultation with the very members who are supposed to be concerned with the development along scientific lines of all schools and scholars. A joint meeting of several sections on "Science and the School," or similar subject, might have suggested a means of adjusting the various claims made upon the curriculum and the resources of schools, and such a meeting should obviously have been held before the Council was asked to father resolutions of individual sections upon subjects which concern other sections also.

We mention this episode merely as an example of the fissiparous tendency of the sections, and as a reason for more frequently dissolving the membrane which separates contiguous cells. When joint meetings are arranged, however, it should be remembered that the larger the intended appeal the more general must be the subject selected, and that the greatest common factor of knowledge possessed by the audience will be correspondingly lower. Huxley once said that in a public lecture he addressed himself to the least intelligent member of his audience, and though it may not NO. 2655 , VOL. IO6] 
be essential for a speaker at a joint meeting of sections to accept this standard, yet if he wishes to claim the close attention of most of his hearers he should not soar so much above it as is commonly done.

What we have said as to the intensive and extensive functions of sections of the Association is on behalf of the general members, who are engaged in scientific education or research. No one waits for an annual meeting of the Association in order to describe a new discovery or announce a development, and as the Association does not publish papers, except by special resolution, there is nothing to induce authors, if they wish their work to be recorded, to make new communications to the sections. The chief aim should be, therefore, not a miscellany of papers of interest to a few specialists, but clear expositions of broad advances which appeal to the many. Beyond this duty of the Association to the general body of scientific workers is the even more important relation of the Association to national life and public interest. 'When the Association first met, and for many years afterwards, it was the only national peripatetic organisation of a scientific or technical kind. Now, however, the Institution of Naval Architects, Iron and Steel Institute, Royal Sanitary Institute, Society of Chemical Industry, Museums Association, Institute of Metals, and other bodies concerned with pure or applied science, hold their annual meetings at different places each year, and the Association no longer occupies a unique position in this respect. Notwithstanding this fact, the Association remains the only body which can represent the contributions of research to the whole field of progressive natural knowledge-whether applied or not-and we believe that a much larger public, in any place of meeting, would take active part in its work if greater consideration were given to wide national questions and the bearing of local conditions upon them.

The Association has come to be regarded as a technical or professional organisation, like the British Medical Association and similar bodies, with the result that the intelligent public in the locality where it meets takes little interest in itat any rate, not so much as it did at one time. At the recent meeting in Cardiff, the total attendance was 1378 ; in 1891 it was 1497 ; and at almost every meeting in recent years the numbers have been less than at the previous meeting in the same place. Scientific workers are much more numerous than they were in the earlier years of the Associa- tion, and the fact that the attendance at meetings does not show a corresponding increase, but a decrease, is a sign that should not be disregarded by an organisation that desires to expand.

Unlike the other societies and institutions mentioned above, the British Association looks for members and support to the public in the locality in which its annual meeting is held. It cannot expect, however, to meet with the response desired unless it does much more to create and foster interest in local and national subjects with which science may be concerned, and by securing for the meetings the presence of prominent public men. Distinguished statesmen, great captains of industry, and leading representatives of labour should be approached, and we believe that many of them would be glad to range themselves on the side of scientific workers and testify to the national significance of contributions to national knowledge. There is no lack of subjects with which such men may be appropriately associated. What is lacking is the eloquent advocacy which well-known public men can give.

We are not alone in suggesting that a change of policy and of programme is needed to bring the Association into line with present conditions. Two of the technical journals-the Electrician and the Chemical Age-have each recently expressed regret that at the Cardiff meeting evidence of progress in electrical science, engineering, and chemistry was not prominently displayed by the papers presented to the sections devoted to these subjects; and they consider that the Association is now out of touch with the times. The former journal suggests that to make the annual meeting of greater interest to the public generally there should be a series of communications on the latest discoveries in physical science, the problems of electric traction, advances in wireless communication, domestic uses of electricity, and related matters in contact with daily life; and it remarks, "We do feel that at a time when electrical science is being more and more applied to the solution of industrial and domestic problems it is a pity that an opportunity such as the annual meeting of the British Association affords of placing what is being done in simple and, so far as possible, in nontechnical language before the general public should have been so conspicuously missed."

Even technical men, therefore, do not look to the Association for specialised work, but for broad surveys of large regions and descriptions of outstanding peaks in scientific fields. Above all, they ask for attention to subjects of vital interest NO. 2655 , VOL. IO6] 
to the community, and this plea is the main object of the present article. The Association should stand not for esoteric, but for exoteric, philosophy, and thus bring within its sphere all who believe that progressive thought, with accurate knowledge, form the only sure foundation upon which man can build a structure that will withstand the polemic storms of the present and the world shocks which promise to assail it in the future.

\section{Ewing's "Thermodynamics."}

Thermodynamics for Engineers. By Sir J. A. Ewing. Pp. xiii +383 . (Cambridge: At the University Press, 1920.) Price zos. net.

$\mathrm{O}^{\mathrm{NE}}$ of the chief fascinations of thermodynamics is the way in which it ramifies into other branches of science, following the manifold transformations of energy. The fundamental laws reappear in so many different aspects in relation to the quantities which are the subject of measurement in the different branches, such as chemistry, electricity, radiation, etc., that it affords one of the most interesting standpoints from which to view the growth of natural philosophy and to study the correlation of its parts. For the same reason it is difficult for the worker in any one branch to follow the applications of thermodynamics to other subjects with the principles of which he is unfamiliar; and he is apt to find that the discussion of his own subject in a general survey is necessarily lacking in the practical details and numerical data which would be required to enable him to make any use of it for his special purpose. Accordingly it is usual in treatises on special subjects, such as steam turbines, or petrol motors, or refrigerating machines, to include one or more chapters on the principles of thermodynamics in relation to the subject discussed. This is a very natural compromise, but involves a great deal of repetition of elementary principles, while it frequently fails, owing to limitations of space or lack of generality, in providing a sufficiently solid foundation for further research. So much effort has been wasted in the past, and is still being wasted, by inventors and experimentalists, in pursuit of fancied improvements which a wider knowledge of thermodynamics would have shown to be illusory, that such knowledge should be regarded as an essential part of the equipment of the scientific engineer, however abstract and theoretical it may appear to the practical man at first sight.

Among English treatises on thermodynamics, few, if any, appear to have been written primarily NO. 2655 , VOL. IO6] from the point of view of the engineer. We are therefore all the more disposed to welcome a book with this object from a master of clear exposition, whose books on kindred subjects are already so well known and appreciated by engineers. The method adopted by the author of the present work is to begin with the elementary notions and their interpretation in practice, and to defer the mathematical relations until the reader may be supposed to have become familiar with the fundamental ideas as physical realities, and is presumably able to apply them to practical problems.

In pursuance of this general scheme, the first six chapters of the book deal with general principles, explained in the first instance in relation to ideal gases, and. then applied to practical problems in discussing the properties of actual fluids, the theory of the steam-engine and of refrigeration, jets and turbines, and internalcombustion engines. Since the general principles of thermodynamics have not changed in the last few years, it naturally follows that most of the material employed in this part of the work is the same as in the author's previous books on "The Steam-engine and Other Heat-engines" and on "The Mechanical Production of Cold." But the material has been rearranged as a connected exposition of the principles, and brought up to date in minor particulars, such as the adiabatic equation for dry steam, and the effect of supersaturation on the discharge through a nozzle. Most of the problems discussed are so well worked out that there is little room for difference of opinion, and so clearly explained that it would be difficult to suggest any improvement. It is only when we come to more recent or debatable problems, especially where the experimental data are still uncertain, that it becomes possible in a few cases to criticise the author's views.

The importance of devoting adequate consideration to the properties of the working fluid as affecting the operation of a heat-engine has been more fully recognised in recent years. Accordingly the author has included in the chapter on internal-combustion engines a discussion of the effect of increase of specific heat at high temperatures, and has added an appendix on the molecular theory of gases, which should serve as a useful introduction to the theory of the variation of specific heat. In discussing this subject the author naturally follows in the main the views of his successor at Cambridge, Prof. B. Hopkinson, whose work he did so much to inspire. Prof. Hopkinson's view that the loss of efficiency, as compared with the ideal air-standard for a given compression-ratio, could be attributed entirely to the increase of specific heat, provides an effective 